\title{
Fabrication of Copper, Brass and 18Cr9Ni Steel Nanoparticles by Laser Ablation Method
}

\author{
Dorota KOCAŃDA ${ }^{1,1}$, Zdzisław BOGDANOWICZ ${ }^{2,1}$, Barbara NASIHOWSKA ${ }^{3,2}$, Roman \\ OSTROWSKI ${ }^{4,1}$, Antoni SARZYŃSKI ${ }^{5,1}$
}

\author{
${ }^{1}$ Faculty of Mechanical Engineering, Military University of Technology, Warsaw, Poland \\ ${ }^{2}$ Institute of Optoelectronics, Military University of Technology, Warsaw, Poland

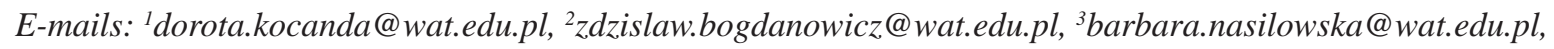 \\ ${ }^{4}$ roman.ostrowski@wat.edu.pl, ${ }^{5}$ antoni.sarzynski@wat.edu.pl
}

\begin{abstract}
The possibilities of nanoparticles fabrication from the selected metals: copper, brass and $18 \mathrm{Cr} 9 \mathrm{Ni}$ steel by laser ablation method were investigated. For the nanoparticles extraction process the most favorable pulse laser parameters were selected such as: laser beam power, number of laser pulses and distance of the beam focus from the metal foil. The SEM analysis confirmed the presence of nanospheres and nanowires geometry of metal particles.
\end{abstract}

KEY WORDS: nanoparticles, laser ablation, copper, brass

\section{Introduction}

Over the past two decades, intensive development of scientific research and practical applications in the field of nanotechnology and science of nanomaterials has been observed. Among nanomaterials, nanometals deserve special attention as various types of nanoobjects with polycrystalline structure such as particles, powders, fibers, layers, etc. having at least one spatial dimension smaller than $100 \mathrm{~nm}$ [1]. The nanometric level in materials means the border of two world, i.e. the word of single atoms and molecules, in which the laws of quantum mechanics apply and the laws of the macroscopic world govern. On a nanometric scale, especially for objects smaller than $5 \mathrm{~nm}$, quantum effects, which determine the physicochemical, biological and mechanical properties of nanomaterials, significantly influence $[1,2]$.

Nanotechnology includes various techniques and methods for design, manufacture and practical use of nanomaterials in equipment, industrial processes and consumer products [4]. Nanotechnology can also be called molecular engineering, because it involves designing and producing new products by placing individual molecules in the right places in the material. The term nanotechnology appeared in the literature after a futuristic lecture entitled: There's plenty of room at the bottom given by physicist Richard Feynmam in 1959, during which he first introduced the term nanorobots, calling such microscopic devices.

Properties of nanomaterials. Nanomaterials are characterized by special physico-chemical, mechanical and biological properties, different from their counterparts with the same chemical composition on a microscopic scale (with dimensions larger than $1 \mathrm{~m}$ ). Small particles cause an increase in the specific surface area of the grain boundaries in a unit volume of material and contribute to their unique properties. This property is associated with the phenomenon of strengthening nanomaterials with grain boundaries [2]. Especially at low temperature, nanomaterials are characterized by very high strength. Different physico-chemical properties of atomic bonds, the presence of defects and stresses in the crystal lattice [1,3].

Another reason of unusual properties of metal nanoparticles is a quantum limitation of electrons in small particles and an increased ratio of the number of atoms or surface ions to the number of atoms or ions inside the particle. The change in the quantum environment of atoms and surface ions in particles affects many nanomaterials to change their properties such as: mechanical (friction, elasticity, plasticity), material (changes in the crystal structure that affect structural stability on a nanometric scale, density, solubility, melting point, electrical conductivity, surface tension, catalytic activity) and spectroscopic properties [3]. An effect occurring on the nanoscale may be the quantum confinement occurring most often in semiconductors, usually when the particles are less than $10 \mathrm{~nm}$, and more precisely, this size depends on the size of the Bohr radius of the exciton in a given material [3].

1 Corresponding author. Tel.: 600270968

E-mail address: barbara.nasilowska@wat.edu.pl 
The spectacular optical effect of this phenomenon is the multi-colored luminescence of quantum dots. Under the influence of UV radiation of a specific wavelength, emission occurs in the visible light range, depending on the size of the nanoparticles forming the macro material. In the first approximation, this can be explained by the increase in prohibited gap, i.e. the distance between the conductor band orbits and the valence band orbits, as the particle size decreases. This means that smaller nanoparticles of a given semiconductor, i.e. CdSe, $\mathrm{CdS}$ or $\mathrm{ZnO}$ will show luminescence shifted towards the blue color under UV radiation, and larger towards the red color. Another example of the phenomena observed only in nanomaterials is the color change of nanostructured metal particles, e.g. gold and silver, which change with color as they decrease from blue (larger particles) to red (smaller particles). It is caused by resonance absorption of radiation by oscillating surface valence electrons, so-called surface plasmon resonance, in metallic nanoparticles. The reason of this phenomenon is the differential absorption of visible light, depending on the size of the nanoparticles. This effect usually occurs when their size is smaller than $150 \mathrm{~nm}$ and is strongly dependent on the material morphology such as shape of particles and material structure $[5,7,8]$. In the plasmon model, the external electromagnetic field oscillates the electron cloud around nanoparticles, originated from the atoms and surface ions of nanoparticles, thanks to which a negative charge is created on the surface of one side of particle and on other side the particle is charged positively. Resonant excitation of the electron cloud by light of a specific wavelength leads to a strong scattering of radiation. In the absorption spectrum there are strong absorption bands for the surface plasmon with characteristic peaks corresponding to specific wavelength. The location of the plasmon absorption bands is characteristic of nanoparticles of a particular metal and strongly depends on the size and shape of nanostructures and their surroundings.

Superparamagnetism. In the case of magnetic properties of nanoparticles, the change occurring on the nanoscale is the phenomenon of superparamagnetism. This phenomenon occurs in ferro- and ferrimagnetics after reducing their particle size to the nanoscale (usually from a few to several dozen nanometers). The critical size conditioning the appearance of this phenomenon depends on the type of material and the value of its magnetic anisotropy depending on the chemical composition, crystal structure and morphology.

Nanoparticles toxicity. The issue of nanoparticle toxicity is currently a very important problem. As already mentioned, nanomaterials often have different properties compared to their counterparts on a macroscopic scale, which also affect their biological properties. Unfortunately, this change is often unfavorable for biological application due to the effect of small nanoparticles. This toxicity may be caused by easier, increased release of heavy metal ions from the surface of nanoparticles, as in the case of quantum dots, such as semiconductors: $\mathrm{CdSe}, \mathrm{CdTe}$ or PbS [10,11]. The cytotoxicity of nanomaterials can also be caused by the porosity of nanoparticles, the tendency to agglomerate, significant chemical affinity for many biological structures, or increased chemical reactivity of their structure [9, 10,11]. Nanoparticles due to their small size can be absorbed as a result of endocytosis by some cells of living organisms and accumulate due to attachment to proteins, cell membranes and other biological structures and can cause damage to cells.

Applications of nanomaterials. The literature on the use of nanomaterials and nanotechnology is very extensive. Nanotechnology is still an inspiration for futuristic vision disseminated in the mass media. However, this information do not always have direct support in the result of scientific research. For this reason they were introduced applications most frequently mentioned in the literature, In medicine, the application of nanomaterials are very diverse and include among others, controlled drug release, targeted therapy, the use of nanomaterials in medical analytics and advanced imaging of organs, tissue and cells. In constructions and various engineering constructional materials, including concrete, steel, plastics, ceramics to improve mechanical or thermal strength, fire resistance, electrical and thermal conductivity. Microelectronics, particularly the production of integrated circuits, microprocessors is basically area of nanotechnology. On the other side, the unusual electrical and optical properties of nanoparticles, graphene, carbon nanotubes indicate the possibility of practical applications in new generation optoelectronic components and systems [4].

Methods of obtaining nanoparticles. The most important nanomaterials include: Ag and Au nanoparticles, $\mathrm{TiO}_{2}$ and $\mathrm{ZnO}$ nanoparticles, $\mathrm{TiO}_{2}$ nanofilms, graphene, carbon tubes, fullerenes.

Nanomaterials can exist in the form of: powder, thin layers or isolated nanometric particles, that are the building material of a given engineering material. Separate nanoparticles can have: a spherical, triangular, pyramid, star, wire and rod -like shape (Fig. 1). The shape of the nanoparticle affects its physico-chemical and mechanical properties. By controlling the conditions of the synthesis properly, we can control the shape and the size of the nanoparticles. 

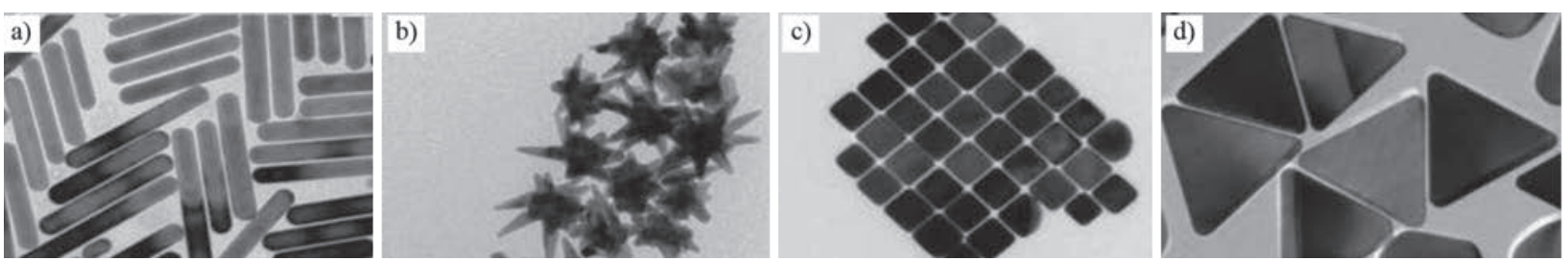

Fig. 1. SEM microscopic image of the gold nanoparticles having different shapes and different sizes: a) nanowires, b) nanostars, c) nanocubes, d) nanoprisms [4].

The methods of producing nanomaterials can be divided into two groups:

1. bottom-up method i.e. the method of building a nanometric structure from single atoms or particles, using their self-organization,

2. top-down method consisting in miniaturization of larger structures.

Bottom-up processes are the chemical synthesis of nanostructures done by [5]:

1. chemical synthesis in the gas, liquid or solid phase,

2. strictly controlled deposition of nanostructures: PVD (Physical Vapour Deposition), CVD (Chemical Vapour Deposition,

3. plasma-supported deposition processes,

4. methods of controlled growth of nanostructures.

In the case of the bottom-up method, nanometals from single atoms or particles can be obtained by vapor or liquid phase deposition of atoms or particles, nanocrystallization from the amorphous phase and consolidation of nanopowders [5].

Top-down methods include physical methods, among them crushing and milling in ball mills or various types of lithography. In the case of nanometals, sever plastic deformation SPD methods play a dominant role among topdown methods.

Monodisperse metal particles can be obtained, among others by following methods: chemical, electrochemical, photochemical, sonochemical and physical method using laser radiation (laser ablation method).

The most commonly used and the simplest method of obtaining metal nano particles is the method of chemical reduction, which is based on the reduction of $\mathrm{M}^{\mathrm{n}+}$ to $\mathrm{M}^{0}$ metal ions [5]. Compare to other methods, it does not require the use of specialized equipment. This method is cheap and at the same time allows to obtain very small colloidal particles, on the order of several nanometers. The choice of a particular method has a direct influence on the quality of the obtained results, i.e. the shape and size of silver nanoparticles. On the nanometric scale, one can also control the macroscopic properties of materials. The selection of appropriate surfactants ensures obtaining nanoparticles with the desired shapes [5].

New research and development opportunities, the ever-decreasing scale of spatial dimensions in optoelectronics as well as the rapid development of the biotechnology industry make research on the production of nanoparticles by laser ablation a necessity. The production of nanoparticles by laser ablation in an aqueous environment has been described in many paper [11-13].

\section{Methodology}

Obtaining nanoparticles of selected metals by laser ablation method. The aim of the work was to demonstrate the possibility of producing nanoparticles from copper, brass and $18 \mathrm{Cr} 9 \mathrm{Cr}$ steel by laser ablation method. For obtaining metal nanoparticles by mentioned method a picosecond pulse laser type EKSPLA PL 2210/SH/TH/ FH was used $[14,15]$. The nominal laser parameters were as follows: pulse energy on the first harmonic $(1064 \mathrm{~nm}$ wavelength) was $3 \mu \mathrm{J}$, on the second one (532nm) - $1.3 \mu \mathrm{J}$, on the third one (355 nm) - $0.9 \mu \mathrm{J}$ and on fourth one (266 $\mathrm{nm})-0.6 \mu \mathrm{J}$, respectively. Duration of the first harmonic pulse was $70 \mathrm{ps}$. The laser operates at a constant frequency of $1 \mathrm{kHz}$. The pulse energy for laser ablation process was regulated by external devices. A half-wave plate with polarizer was used to regulate energy of laser beam. To improve the quality of the beam, a telescope widening the beam diameter five times and a diaphragm with diameter of $6 \mathrm{~mm}$ cutting out the central part of the beam was used. As a result of this action at the scanner input, the maximum pulse energy on the $3^{\text {rd }}$ harmonic did not exceed $380 \mu \mathrm{J}$. With the help of a polarizing attenuator, the pulse energy could be manually reduced even to individual microjoules. Structural studies of the obtained nanoparticles were performed using the Quanta 250 FEG scanning electron microscope. 


\section{Results}

The selection of the most favorable laser parameters was carried out in terms of laser beam power, number of pulses and distance of the beam focus from the metal foil. In each case of the tested parameters of the laser ablation process, microscopic analysis of the obtained product in the form of dust of metal particles was carried out using SEM microscope.

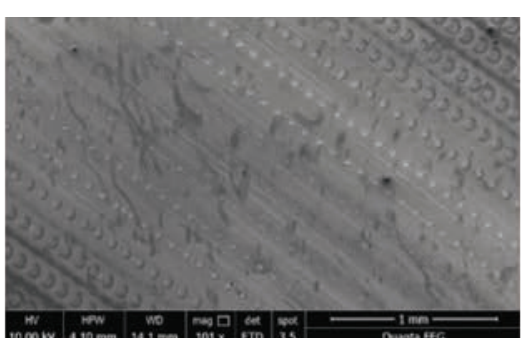

Fig. 2. Selection of laser ablation parameters for the production of nanoparticles.

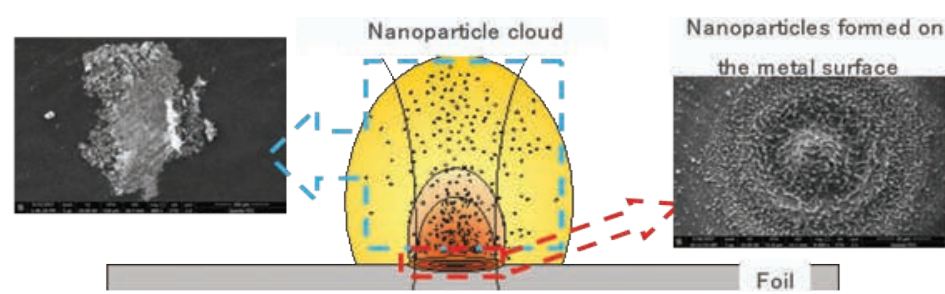

Fig. 3. Scheme of laser beam interaction on metal in laser ablation process.

This analysis showed that for copper foil of $25 \mathrm{~mm}$ thickness the most favorable laser parameters at which nanoparticles occur are: focal distance from the metal foil $\mathrm{z}=63.8 \mathrm{~mm}$, laser pulse energy $\mathrm{E}=31 \mathrm{~mJ}$, the number of impulse Ls=40 (Fig. 2). The scheme of the laser beam interaction on the analyzed metal alloys is shown in Fig. 3.

It was noted that the produced nanoparticles did not have equal dimensions. It can be assumed that by optimizing the laser ablation process and appropriate segregation of a selected batch of samples it will be possible to obtain particles of equal dimensions. The scheme of nanoparticles production is shown in Fig. 3.

During each exposure of metal with a pulsed laser beam with optimized parameters, local metal evaporation from the resulting crater occurred. Evaporated metal particles formed a cloud of nanoparticles, which settling mainly near the beam focus, but not directly in the axis of its interaction. After the laser ablation process was completed, crystallization of needle-shaped single crystals with nucleating dendrites lateral branching was observed on the textured surface of copper foil (Fig. 4a). Copper single crystals in the form of nanowires (Fig. 4b) also nucleated on the spherical surface of the nanospheres, which detached from the metal surface. The effect of longer laser pulses resulted in a significant increase in lateral branches of dendrites.

During the analysis of the geometry of produced nanoparticles, apart from nanowires that detached from the metal surface in the sublimation process (Fig. 4a), spherical copper monocrystals (nanospherolytes) in the form of nanospheres (Fig. 4b) with regular shapes were observed. The size of the obtained nanospheres was determined by the parameters of the laser ablation process used.
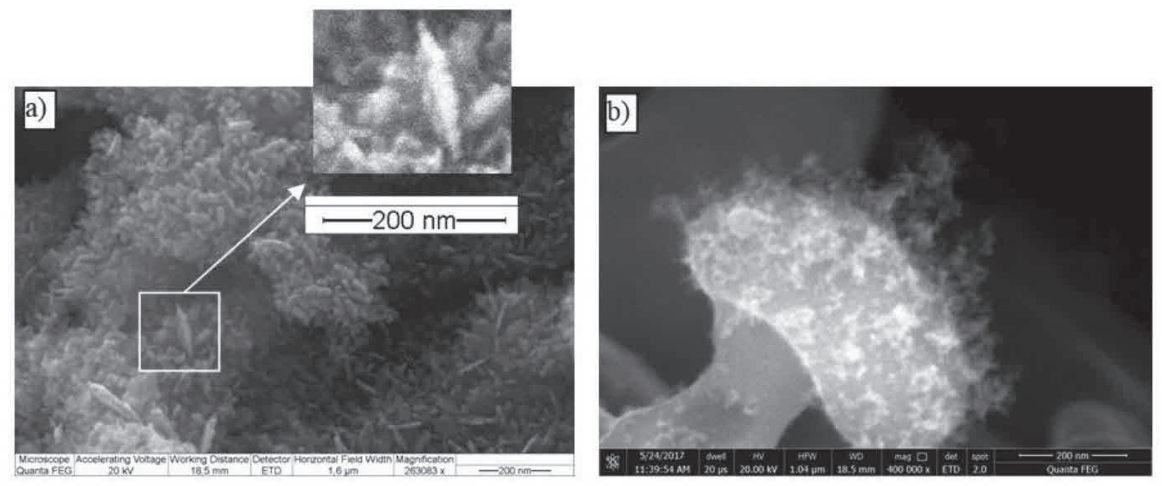

Fig. 4. SEM image of copper single nanocrystals with nucleating dendrites lateral branches (a), nanowires on the copper surface in the form of dendrites with developed branches on the spherical surface detached from the metal surface in the process of laser ablation (b).

The analysis of the influence of laser ablation process parameters on the obtained size of nanospheres results that in order to produce nanoparticles with diameters in the determined range following parameters are required:

1. from 25 to $100 \mathrm{~nm}$, the use of laser pulse energy $E=31 \mathrm{~mJ}$, the number of pulses $\mathrm{Ls}=40$ and the location of the beam focus from the metal surface at a distance $=63.8 \mathrm{~mm}$, 
2. from 100 to $400 \mathrm{~nm}$ it requires the use of laser energy $\mathrm{E}=31 \mathrm{~mJ}$, the number of pulses $\mathrm{Ls}=40$ and the location of the beam focus from the metal surface at a distance $=64 \mathrm{~mm}$.

A small changes in the beam focus distance from the surface of the metallic material amounting to $0.2 \mathrm{~mm}$ significantly influenced the process of manufacturing nanoparticles by laser ablation from copper (Fig. 5), 18Ni8Cr steel (Fig. 6) and brass (Fig. 7).
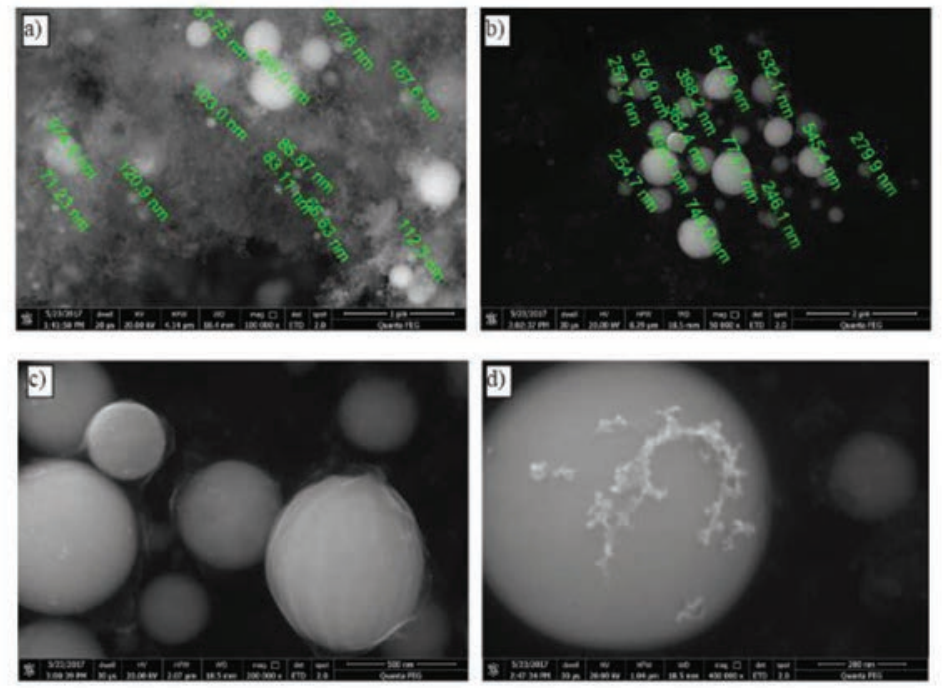

Fig. 5. SEM image of copper nanospheres formed in the laser ablation process.

During the analysis of the nanoparticles geometry, apart from nanowires that detached from the metal surface in the sublimation process (Fig. 7a), spherical nanocrystals (nanospherolytes) in the form of nanospheres (Fig. 7 b-d) with regular shapes were observed. The size of the obtained nanospheres was determined by the parameters of the laser ablation process used.

The results of tests carried out using the SEM microscope, it was observed that the resulting metallic nanoparticles of spherical shape did not tend to agglomerate, unlike nanowires. This is due to the increase in Van der Waals forces in interactions between particles as their size decreases.
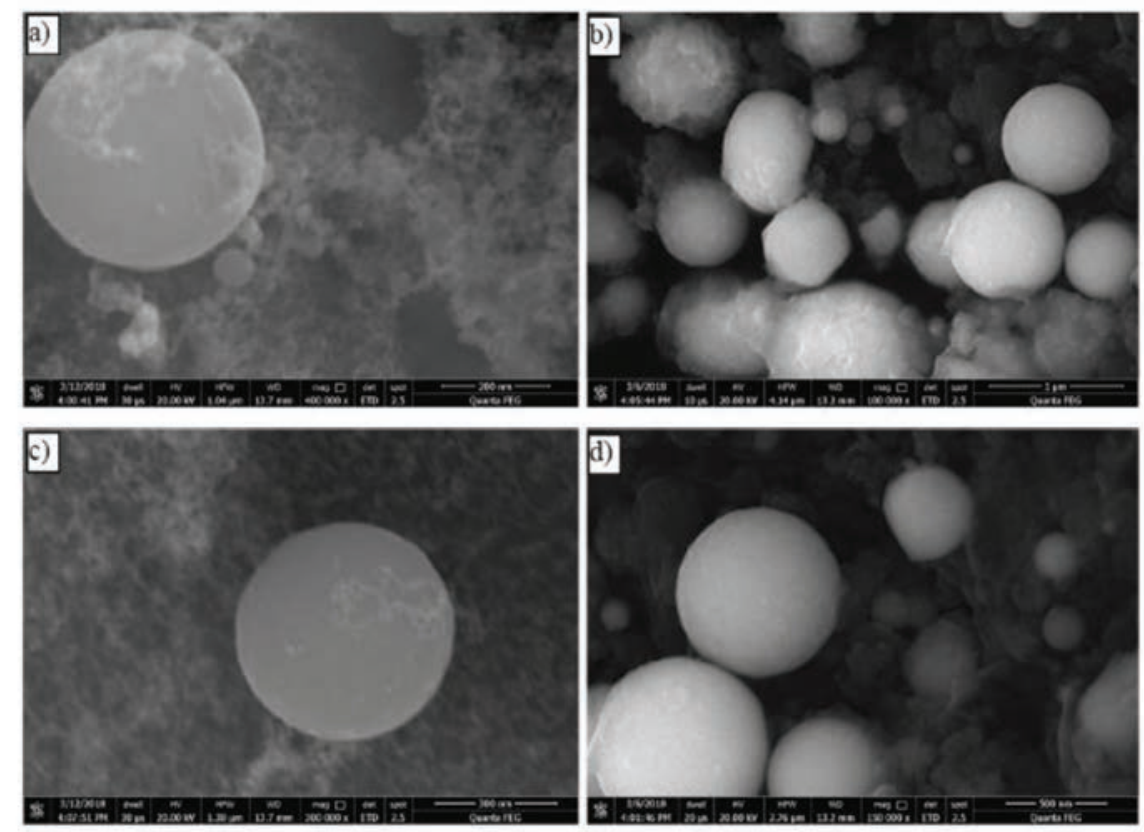

Fig. 6. SEM image of nanospheres of the $18 \mathrm{Cr} 9 \mathrm{Ni}$ steel formed in laser ablation process. 

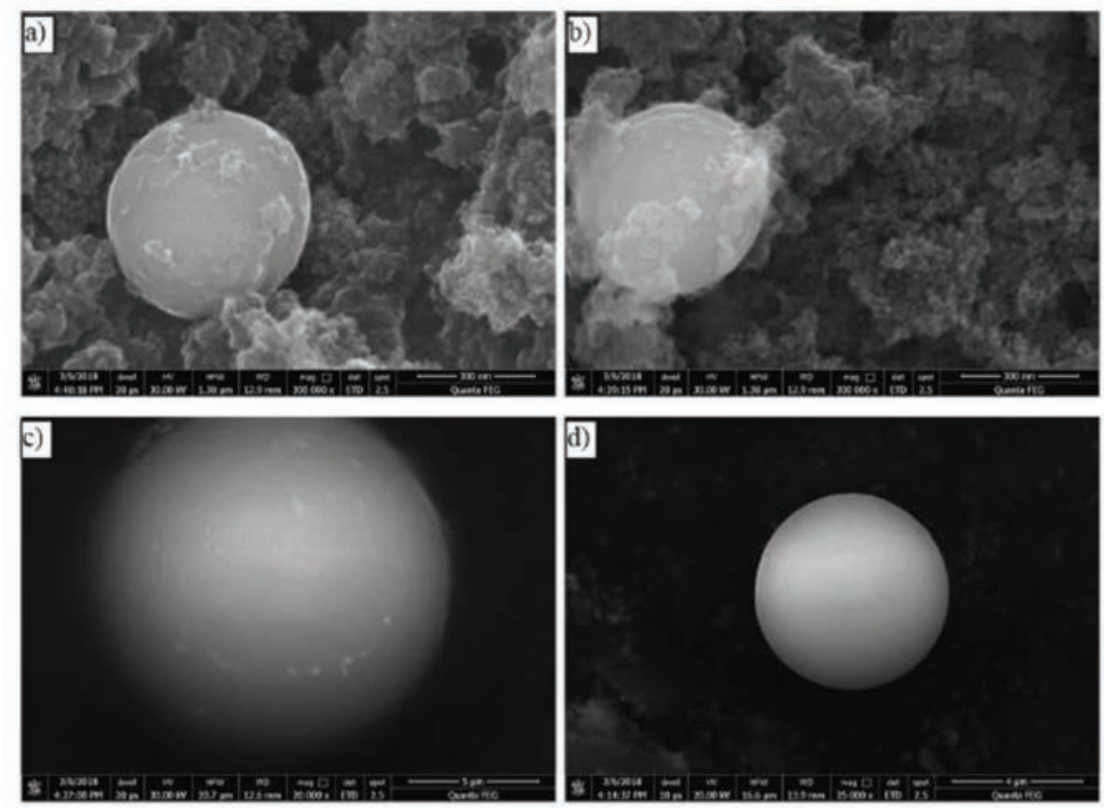

Fig. 7. SEM image of nanospheres of the brass formed in laser ablation process.

Agglomeration consisted of the nanoparticles sticking together without changing their internal structure by reducing surface energy [16].

In order to confirm the effectiveness of the method used for the production of metal nanoparticles of spherical shape, laser ablation was also performed for $18 \mathrm{Cr} 9 \mathrm{Ni}$ steel foil (Fig. 7) and brass foil (Fig. 6) with 25 mm thickness.

It was noted that the obtained nanoparticles did not have equal dimensions. It can be assumed that by optimizing the laser ablation process and appropriate segregation of a selected batch of samples it will be possible to obtain particles of equal dimensions.

\section{Conlusions}

By means of laser ablation nanoparticles can be obtained in the form of nanowires and nanospheres without the use of additional substances and a synthesis substrate. The method is economical and easy to implement. However, the problem is the controllability of the laser ablation process in which nanoparticles with precisely defined dimensions, e.g. only $100 \mathrm{~nm}$, are produced.

Monocrystalline nanowires were mainly located on the surface of the metallic foil, while dendritic nanowires and nanospheres were observed in the collected cloud of particles after the sublimation process. The most favorable laser parameters at which dendritic nanowires occurred were following: focal distance from the metal foil $\mathrm{z}=64 \mathrm{~mm}$, laser pulse energy $\mathrm{E}=31 \mathrm{~mJ}$ and the number of impulse $\mathrm{Ls}=40$.

Preliminary tests have also confirmed possibility of obtaining by laser ablation process nanosheres from other materials, i.e. brass and $18 \mathrm{Cr} 9 \mathrm{Ni}$.

\section{References}

1. Kurzydłowski K., Lewandowska M. Nanomateriały inżynierskie konstrukcyjne i funkcjonalne, 2010, WN PWN SA, Warszawa.

2. Marzec A., Pulit J., Kwaśny J., Banach M. Nanometale - wybrane technologie wytwarzania. Chemia. CT, WPK, 2012, 16.

3. Runowski M. Nanotechnologia - nanomateriały, nanocząstki i wielofunkcyjne nanostruktury typu rdzeń/ powłoka. Chemik, 2014, (68), p.766-775.

4. Makowski W. Nanotechnologia, Nanomateriały, Wydział Chemii, UJ, Otrzymywanie nanocząstek złota, srebra i miedzi metodą redukcji chemicznej. Katedra Technologii Środowiska Wydział Chemii UG - Ćwiczenia Laboratoryjne, 2015.

5. Giersig M., Et Al. J. Phys. Chem., B. 1999, 103, p. 33-9539.

6. Fischer Ch., Giersig M. Journal Of Chromatography A 688 1994, 1-2, p. 97-105.

7. Khan I., Saeed K., Khan I. Arabian Journal of Chemistry, 2017.

8. Kutvonen A., Rossi G., Puisto S.R., Rostedt N. K. J., Ala Nissila T. Influence of nanoparticle size, loading, and 
shape on the mechanical properties of polymer nanocomposites. J. Chem. Phys. 2012, 137, 214901.

9. Langauer-Lewowicka H., Pawlas K. Nanocząstki, nanotechnologia - potencjalne zagrożenia środowiskowe i zawodowe. Medycyna środowiskowa, 2014, 17, (2), p. 7-14.

10. Dell'Aglio, Gaudiuso M., De Pascale R., De Giacomo O. Mechanisms and processes of pulsed laser ablation in liquids during nanoparticle production. Applied Surface Science, 2015, 348, p. 4-9.

11. Liu J., Hu R., Zhang B., Wang Y., et al. Cytotoxicity assessment of functionalized CdSe, CdTe and InP quantum dots in two human cancer cell models. Mater. Sci Eng C Mater Bio Appl., 2015, 1, (57), p. 222-231.

12. Kulinich S.A., Kondo T., Shimizu Y., Ito T. Pressure effect on ZnO nanoparticles prepared via laser ablation in water. Journal of Applied Physics, 2013, 113, (3), 033509.

13. Myungjoon K., Saho O., Taesung K., Hidenori H., Takafumi S. Synthesis of nano-particles by laser ablation. Kokona Power and Particle Journal, 2017, 34, p. 80-90.

14. Nasiłowska B., Bogdanowicz Z., Sarzyński A., Skrzeczanowski W., Djas M., Bartosewicz B., Jankiewicz B.J., Lipińska L., Mierczyk Z., The influence of laser ablation parameters on the holes structure of laser manufactured graphene paper microsieves Materials, 2020,13, (7), 1568.

15. Lapiński M., Bogdanowicz Z., Marczak J., Rycyk A., Sarzyński A., Strzelec M., Laser manufacturing of microsieves for bioengineering applications, Photonics Letters of Poland, 2015, 7, (3), p. 60-62.

16. Żelechowska K. Nanotechnologia w chemii i medycynie, WPG, 2014. 